\title{
Solutions for Digitalization of the Coal Industry Implemented in UC Kuzbassrazrezugol
}

\author{
Yuri Semenov ${ }^{1, *}$, Olga Semenova ${ }^{1}$, and Ildar Kuvataev ${ }^{2}$ \\ ${ }^{1}$ T.F. Gorbachev Kuzbass State Technical University, 650000 Kemerovo, 28 Vesennyaya St., Russian \\ Federation \\ ${ }^{2}$ Kazakh Humanitarian Juridical Innovative University, EKR, Semey, 11Mangilik st., Republic of \\ Kazakstan
}

\begin{abstract}
According to the article, digitalization and optimization of the coal industry are to continue within the framework of the National Technology Initiative (NTI), the Strategy for Scientific and Technological Development of the Russian Federation, and the Digital Economy Programme. At the initial stage of modernization, the suggested mathematical and software tools will allow creating a smart digital twin of the supply chain. This digital twin will simplify obtaining comprehensive data about the interaction of the focal coal mining enterprises and contractors, carrying out simulation experiments based on various input data, and analyzing the impact of inventory management and transport policies on the system performance. The digital model will enable the coal companies management to find reserves for optimization and transformation of all links in the added-value chain.
\end{abstract}

\section{Introduction}

Currently, acceptance of advanced manufacturing technologies in all essential sectors of the national economy is the subject of wide speculation. The National Technology Initiative, The Strategy for Scientific and Technological Development of the Russian Federation, and the Digital Economy aim at paving the way within the country for the development of sectors that will become leaders of the global economy. Each of the programmes contains a part focused on the modernization and digitalization of the mining industry.

TechNet, being analogous to the German programme "Industry 4.0", is one of the NTI markets. TechNet provides for measures to ensure the rapid development of the Russian Federation in the future through creating or transforming high-tech industries that are crucial for maintaining national security and improving the standard of living [1]. Big Data and Business Analytics, Digital Modelling, Industrial Internet of Things, Autonomous Robots, Augmented Reality, Horizontal and Vertical System Integration, Cloud Technologies, Additive Technologies, Information Security will result in optimization, robotization and digitalization of the working process in the coal industry [2]. The transition from embedded systems to cyber-physical systems (CPS), based on the

\footnotetext{
*Corresponding author: semenov63@mail.ru
} 
interaction of Internet-connected devices with each other, will allow an enterprise, industry, or country to take a leading position in the international market.

The Strategy for Scientific and Technological Development of the Russian Federation, among other issues, prioritizes more efficient production of raw hydrocarbons and their deep processing, energy generation from new sources, development of energy transportation and modes of energy storage [3]. As for the coal industry, the Strategy highlights the design and use of new equipment, the development of technologies for mineral exploration, extraction, bending, etc.

The national project "Digital economy" ensures the transformation of the socioeconomic sphere of mineral resource clusters through the introduction of digital technologies and platform solutions [4]. This programme provides for both vertical and horizontal digitalization of all processes not only for the focal enterprise (open-pit mine, mine, or factory) but for all participants in the added-value chain. Creating smart digital twins of supply chains allows us to visualize all the participants of the value-added activity, analyze the position of the enterprise in the overall cost system and, as a result, achieve competitive advantages [5].

According to the generally accepted terminology [6], there are 3 types of Factories of the Future that combine breakthrough technologies to create globally competitive products of a new generation:

- Smart Factories (also Smart Manufacturing), which operate based on the principle of flexible production and the use of automated and robotic systems for managing production processes;

- Virtual Factories (also Virtual Manufacturing Network), which are a managed chain to generate the product value;

- Digital Factories, which are for designing and modelling products, developing Smart Digital Twins or Digital Mock-Ups (DMUs).

\section{Experimental Research Method}

The relative stability of the supply chain for the finished product delivery is a distinctive feature of the coal industry. Contracts for the energy supply are usually long term, and consumers are already known. Equipment and spare part suppliers have a stable position in the market. The end product has a set of properties depending only on the extraction spot (oxidation group; lump sizes; moisture, ash, sulfur and impurities content; calorific value; volatile substances, etc.). Taking into account the customer's demand for specific grades of coal, we can preplan coal production for each open-pit mine (Fig. 1). The Smart Factory concept implies demand-dynamic performance. It is possible to achieve the aim by using installed modules that ensure an adequate response to the changing demand for coal by increasing or reducing coal production, as well as redistributing and relocating production facilities and labour force among mines or open pits. Such mining equipment as drilling machines, excavators, transport machines, mining-and-hauling machines, dump-forming machines, sorting and processing equipment and machines for auxiliary works can act as relocatable production facilities. 


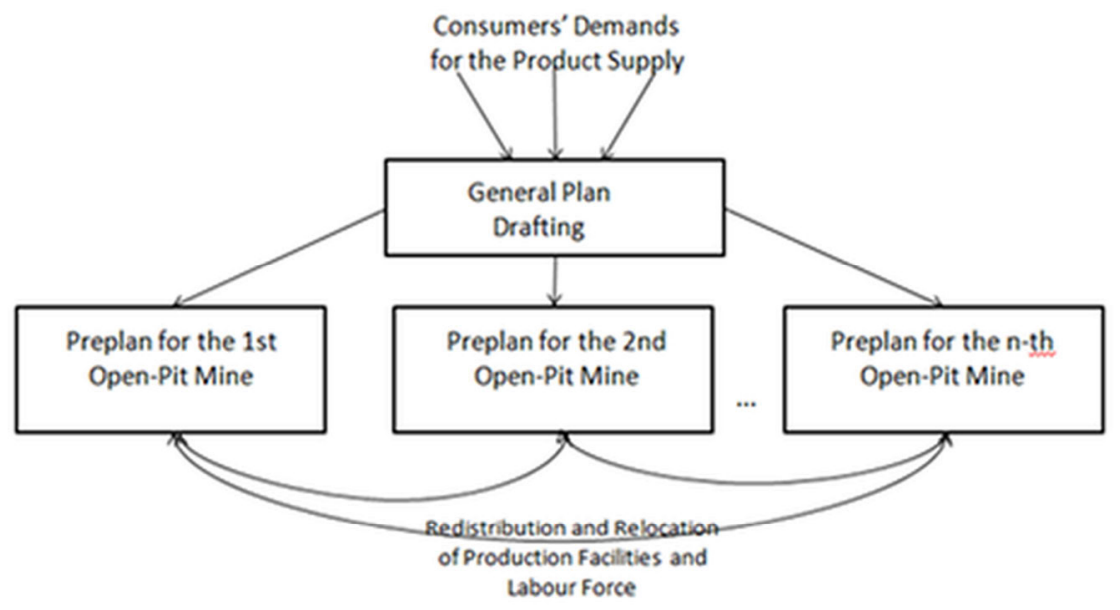

Fig. 1. Redistribution and Relocation of Production Facilities and Labour Force among the Mines or OPMs Depending on the Customers' Demands.

The problem of finding the optimal plan for the redistribution of the resources can be stated as a linear programming problem

when

$$
\sum_{i=1}^{m} \sum_{j=1}^{n}\left(c_{i j} x_{i j}+s_{i j} y_{i j}\right) \rightarrow \min ,
$$

$$
\left\{\begin{array}{c}
\sum_{j=1}^{n} x_{i j} \leq a_{i}, i=1,2 \ldots m, \\
\sum_{i=1}^{m} x_{i j} \geq b_{j}, j=1,2 \ldots n, \\
\sum_{j=1}^{n} y_{i j} \leq d_{i}, i=1,2 \ldots m, \\
\sum_{i=1}^{m} y_{i j} \geq g_{j}, j=1,2 \ldots n, \\
x_{i j} \geq 0, y_{i j} \geq 0, \text { for all } i \text { and } j,
\end{array}\right.
$$

where $a_{i}$ - the number of production facilities available for relocation in point $i$,

$b_{j}$ - the number of production facilities required for production in point $j$,

$c_{i j}$ - cost of transporting a production facility from the $i$-th to the $j$-th point,

$x_{i j}$ - the number of production facilities that are redistributed from the source point to the destination point,

$d_{i}$ - the share of available labour force for relocation in point $i$,

$g_{j}$ - the share of labour force required for production in point $j$,

$s_{i j}$ - cost of transporting a unit of labour force from the $i$-th to the $j$-th point,

$y_{i j}$ - the number of labour force units that are redistributed from the source point to the destination point.

Since besides the one-time relocation of the necessary mining equipment to the mining sites, regular transportation of the labour force is required, the classical transport problem 
statement introduces an additional term $-s_{i j} y_{i j}$. However, in the conditions of a Smart Factory and untended production the variable $y_{i j}$, describing the relocation of the labour force will tend to zero.

A rise in the profitability of coal enterprises will result from qualitative or quantitative changes in the management structure, changes in the technology of coal extraction or bending, quality improvement, etc. To improve the quality of coal products is possible through coal grading and bending, employing advanced manufacturing technologies for coal extraction and processing. However, the major part of the coal companies has already solved these issues. For example, UK Kuzbassrazrezugol has developed a programme to increase processing capacity, according to which existing coal processing plants and new ones are in the process of on-going development and construction. As a result, since 2011, the volume of coal processing has increased from 71 to $89 \%$ of total production.

Virtual Factories allow one to implement qualitative changes, not in the product, but the supply chains by reducing the waiting time for an order, increasing the level of service, reducing risks, etc. Supply chain management integrates production and logistics processes at several levels. Strategic issues comprise such solutions as the size and location of developed fields, coal storages or concentrating factories, the structure of service networks, supply chain design. Tactical issues include planning production, transportation, and stock control, while operational issues involve management of coal mining and processing, inventory, and vehicle routing.

\section{Results and Discussion}

Two types of supply chains are characteristic of the coal mining industry, one includes a concentrating factory, and the other one doesn't. Since a coal company usually consists of several colliers with their supply chains, it is necessary to unite all the available supply chains into a global one (Fig. 2). This global chain contains colliers (open-pit mines OPM1, $\mathrm{OPM} 2, \ldots \mathrm{OPMm})$, coal storages (CS1, CS2, .. CSm), concentrating factories (CF1, CF2, ... CFk) and consumers (Customers $\mathrm{C} 1, \mathrm{C} 2, \ldots, \mathrm{Cs})$.

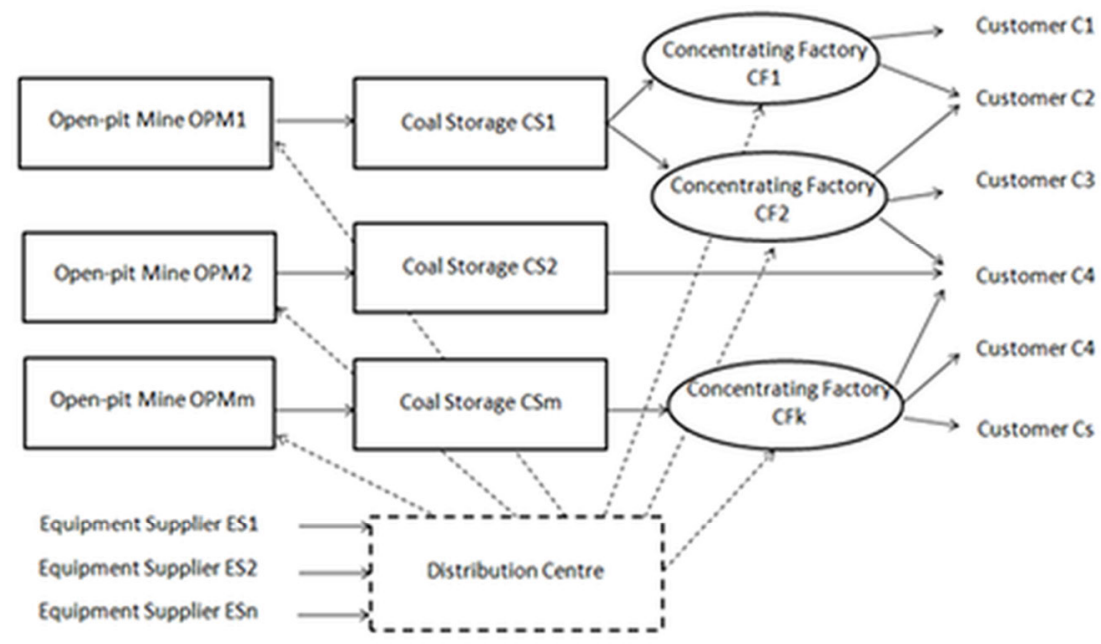

Fig. 2. Coal Production Supply Chain.

The main risks affecting the supply chain of coal products can be as follows:

- risks that result from disruption of coal production at the open-pit mine; 
- risks of disruption of product deliveries by transport companies;

- risks of disruption of shipment of the finished products;

- financial risks caused by currency exchange rate changes;

- risks generated by problems in concentrating factory operation.

The AnyLogistix simulation programme enables modelling a supply chain digital twin and assessing all types of risks. The programme allows its users to obtain the necessary data about the network operation and analyze this information for decision-making.

Let's consider the supply chain modelling using the example of the UK Kuzbassrazrezugol, which includes such branches (OPMs) as Kedrovsky, Mokhovsky (including the Baykaim OPM), Bachatsky, Krasnobrodsky, Taldinsky, and Kaltansky.

The input information for developing the model is a set of structured data that characterize each node in the supply chain (Table 1). Since equipment suppliers ES1, ES2, ... ESn (Supplier Sn) hardly affect the added-value chain of the coal products we can neglect their value and not include in the global supply chain.

Table 1. Data for developing the model.

\begin{tabular}{|l|l|}
\hline \multicolumn{1}{|c|}{ Supply chain node } & \multicolumn{1}{c|}{ Data } \\
\hline Open-pit mine OPMm & The OPM location, the products manufactured and their properties \\
\hline Coal storage CSm & $\begin{array}{l}\text { The CS location, inventory of the products in-store; facility expenses; } \\
\text { processing costs; storage capacity }\end{array}$ \\
\hline Concentrating factory CFk & $\begin{array}{l}\text { The CF location, range of the products to process, range of the end } \\
\text { products; facility expenses; order processing costs; CF capacity }\end{array}$ \\
\hline Customer Cs & Customers' location, ordered products, order dynamics \\
\hline
\end{tabular}

Each node in the supply chain produces, processes, stores, or transports a specific type of coal product. For example, Kedrovsky OPM produces the SS coal (low-caking), Kedrovskaya concentrating factory bends it. The coal grades produced at the factory are SSPK (low-caking, lump, large), SSOM (low-caking, nut, small), SSSSH (low-caking, pea, dust), SSMSSH (low-caking, small, pea, dust), SSPKO (low-caking, lump, large, nut), KSNOM (coking, low-caking, low-metamorphized). The coal shipment depends on the consumers' demand. The table "Demand" of the AnyLogistix simulation programme has information about its type and determinants. For modelling, we also need the data concerning the manufactured products, i.e. the cost of production and bending of each grade of coal at each open-pit mine, the sale price, the cost of transportation by various modes of transport, etc.

In the process of modelling using real data, we get a smart digital twin of the global supply chain (Fig. 3). The chain twin can highlight the impact of production policies and distribution policies upon the supply chain; evaluate the effectiveness of logistics; determine ways to improve the supply chain efficiency; eliminate bottlenecks, and simulate risks. By setting various transport policies, inventory management policies in coal storages, and carrying out simulation experiments, we can get the optimal ELT (expected lead time) service level, the order waiting time, total costs, and other KPIs. 


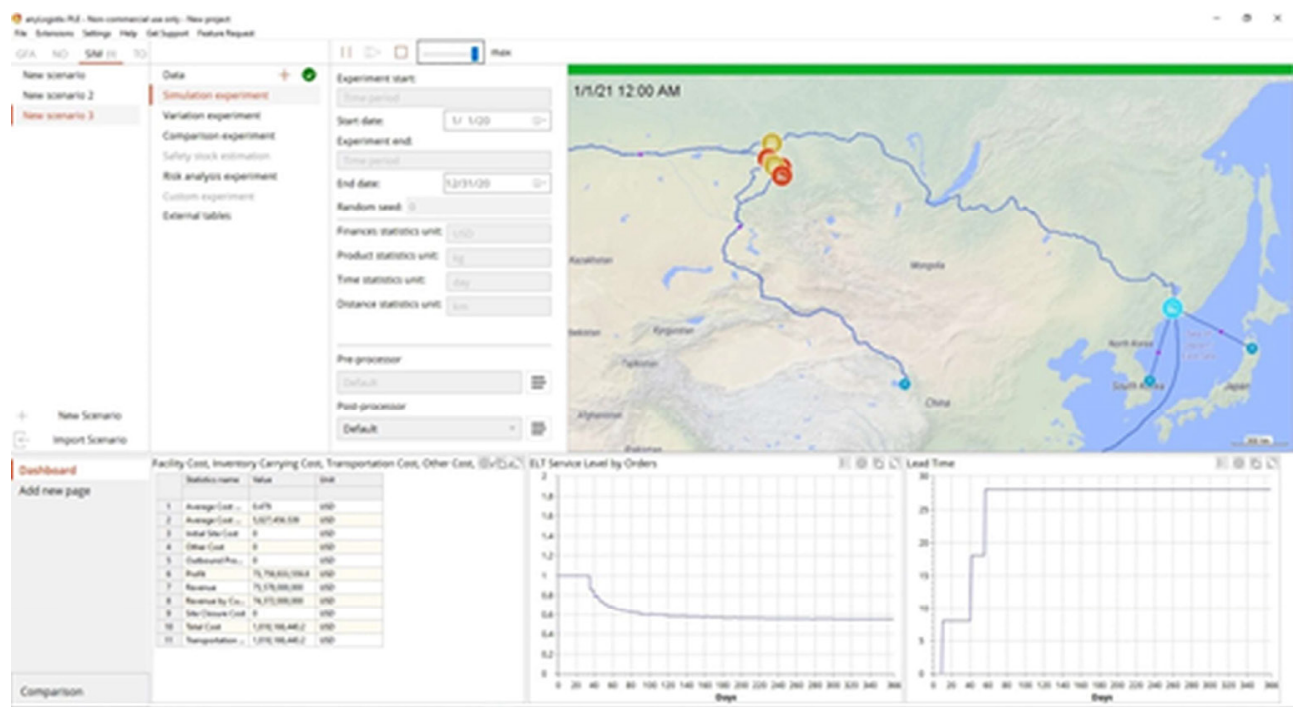

Fig. 3. Global Supply Chain Model.

By creating a smart digital twin of the supply chain, we can get comprehensive information about its current state, plan innovations, and experiment with its structure and elements.

\section{Conclusions}

Optimization and modernization of the coal industry are unthinkable without the use of innovative and digital technologies. The article suggests using mathematical and software tools that allow creating a smart digital twin of the supply chain of coal products. Working with the logistics system model makes it much easier to analyze the interaction of supply chain nodes, assess risks, and evaluate the current inventory management and transportation policies for finished products. Thus, working with a smart digital twin enables the coal company management to find reserves for optimizing and transforming all links in the added-value chain.

\section{References}

1. Government of the Russian Federation, Resolution of 18.04.2016 N317 "On the Implementation of the National Technology Initiative" (Russian Newspaper, Moscow, 2016)

2. Yu. A. Plakitkin, L. S. Plakitkina, Mining Industry, 1, 22 (2018)

3. The President of the Russian Federation, Decree of 01.12.2016 N 642 "On the Strategy for Scientific and Technological Development of the Russian Federation" (Russian Newspaper, Moscow, 2016)

4. M. E. Porter, Competitive Advantage: Creating and Sustaining Superior Performance (The Free Press, New York, 1985)

5. M. Gaillard, Grands défis pour Horizon 2020 (FutuRIS, Paris, 2012)

6. J. Davis, T. Edgar, J. Porter, J. Bernaden, M. Sarli, Computers \& Chemical Engineering, 47, 145 (2012) 
7. A. Azevedo, A. Almeida, Robotics and Computer-Integrated Manufacturing, 27, 755 (2011) 